\title{
Simple method of evaluating vectorcardiographic loops in children
}

\author{
Kalim-Ud-Din Aziz, R. Curtis Ellison, Olli S. Miettinen, and Richard S. Jones \\ From the Department of Cardiology, Children's Hospital Medical Center, and the \\ Department of Pediatrics, Harvard Medical School, Boston, Massachusetts, U.S.A., and the \\ Heart Clinic, Royal Liverpool Children's Hospital, Liverpool, England
}

From the Frank vectorcardiograms of IOI normal children between 3 and I 4 years of age, percentile vector tables and charts have been constructed for the horizontal, frontal, and left sagittal planes. The use of these charts allows a rapid analysis of unknown vectorcardiograms by demonstrating where normal limits are exceeded.

As an initial test of the method, the vectorcardiograms of 20 patients with aortic stenosis and 20 patients with pulmonary stenosis were analysed in the horizontal plane. For the aortic stenosis patients, 19 of the 20 exceeded the 95th percentile limits in the posterior quadrants, and all 20 of the patients with pulmonary stenosis exceeded the 95th percentile limits in the right quadrants.

Thus, it appears that the method described allows a rapid means of detecting abnormality of vectorcardiograms, and in an initial test appears to be quite sensitive. The use of normal percentile charts and tables should make feasible the routine analysis of vectorcardiograms in clinical practice.

The vectorcardiogram is said to have significant advantages over the standard electrocardiogram in the assessment of many types of congenital heart disease (Hugenholtz and Liebman, 1962; Gamboa, Hugenholtz, and Nadas, 1965). Because the parameters usually measured, such as timed vectors or spatial voltages (Young, Liebman, and Nadas, 1960; Hellerstein and Hamlin, 1960; Hugenholtz and Liebman, 1962), are rather complex, the vectorcardiogram has not had widespread clinical acceptance in routine cardiac evaluation.

With the aim of facilitating routine clinical application of the vectorcardiogram, the present study was undertaken to determine, for normal children, the voltage distributions in various directions of each of the three planar projections, and to present them in a form that could be used readily for diagnostic evaluation of vector loops. The applicability of the procedure was tested in the assessment of left and right ventricular hypertrophy in patients with aortic and pulmonary stenosis, respectively.

\section{Received I March 197 I.}

1 Supported in part by grants from the National Heart and Lung Institute of the National Institutes of Health, Bethesda, Maryland, U.S.A.

\section{Materials and methods}

A total of ror children was included in the normal series. The absence of cardiovascular disease was inferred from a negative clinical history and physical examination obtained by a cardiologist. The standard electrocardiogram did not show any abnormality. The children had been admitted to the Alder Hey Children's Hospital in Liverpool for various short-term illnesses, such as minor trauma, upper respiratory tract illnesses, ear, nose, and throat infections, and behaviour problems. The children varied between 3 and 14 years of age and there were 8 to Io subjects at each year interval (Io between 3 and 4 years, 9 between 4 and 5 years, etc.). There were 65 boys and 36 girls.

The vectorcardiograms were obtained, just before discharge from the hospital, by means of a Sanborn vectorcardiograph (Sanborn 185 vector system) modified for the Frank lead system (Frank, 1956). The praecordial leads were placed at the level of the 4th intercostal space. The calibration was adjusted so that one millivolt produced a deflection of 50 centimetres. The recording was interrupted at $2.5 \mathrm{msec}$ intervals. The loops in the horizontal, frontal, and left sagittal planes, for each vectorcardiogram, were converted to directional voltage values by the use of an ' $\mathrm{X}-\mathrm{Y}$ ' digitizing table connected on-line to a PDP-9 digital computer ${ }^{2}$ at the Children's Hospital Medical Center, Boston, Massachusetts. The 2 Digital Equipment Corporation, Maynard, Massa-
chusetts, U.S.A. 
vector forces were measured from the ' $E$ ' point at ro degree angle intervals.

In each plane, and for each of the directions considered, the distribution of voltages was characterized by a selected set of percentiles. Graphic loops were then constructed by connecting the corresponding percentile points in the different directions of any given projection. The direction of the horizontal and left sagittal planes for graphic presentation was counterclockwise in all cases. Because of the overlap of the initial and terminal forces in the frontal plane, the direction was not taken into account.

Percentile connecting loops of the above type were constructed on transparent paper for superimposition on individual vectorcardiograms, matching the $E$ point and the axes (see Fig. 4). Such loops, based on selected percentile values, were used to determine the frequencies with which the loops under study protrude outside the superimposed reference loop and in which quadrants these high voltages occur. This was done first on the normal series to evaluate specificity. Then, for the purpose of gaining some idea of sensitivity, cases of aortic and pulmonary stenosis were studied. There were 20 patients with pure valvar aortic stenosis, with left ventricular pressures ranging from 150 to $280 \mathrm{mmHg}$ (mean $=188$ $\mathrm{mmHg}$ ), and 20 patients with pure valvar pulmonary stenosis with right ventricular pressures between 69 and $103 \mathrm{mmHg}$ (mean $=91 \mathrm{mmHg}$ ). All these children had been studied by cardiac catheterization at the Children's Hospital Medical Center, Boston, Massachusetts. The age range of these patients was from 3 to 14 years, as with the normal subjects. The horizontal plane was used, since it is more sensitive than the other two projections in the detection of ventricular hypertrophy.

\section{Results}

Selected percentiles of directional voltages in the horizontal, frontal, and left sagittal projections are given in Tables 1,2 , and 3, respectively, and partially illustrated in Fig. $\mathrm{I}, 2$, and 3 .

When screening for a totally unspecified abnormality it is necessary to consider all parts of the loop. The loop connecting the directional 95th percentiles in the horizontal projection was evaluated in this way. The horizontal plane loops in 22 of the normal subjects were not completely contained within the reference loop. Thus, the false positive rate of this procedure and criterion may be estimated as 22 per cent, which corresponds to a specificity of 78 per cent. In 19 of these the positive finding arose in one quadrant only, and in the remaining 3 it occurred in two quadrants for each subject. The frequencies of false positive values for the left anterior $\left(0-90^{\circ}\right)$, right anterior $\left(90-180^{\circ}\right)$, right posterior $\left(180-270^{\circ}\right)$, and left posterior quadrant $\left(270-360^{\circ}\right)$ were $7,3,8$, and 7 ,
TABLE I Horizontal plane: vector values in millivolts

\begin{tabular}{|c|c|c|c|c|c|c|c|c|}
\hline \multirow{2}{*}{$\begin{array}{l}\text { Angle } \\
\text { in } \\
\text { degrees }\end{array}$} & \multicolumn{8}{|c|}{ Percentiles } \\
\hline & $\begin{array}{l}\text { Mini- } \\
\text { mum }\end{array}$ & 5 & 20 & 50 & 80 & 95 & 99 & $\begin{array}{l}\text { Maxi- } \\
\text { mum }\end{array}$ \\
\hline 0 & 0.40 & 0.46 & 0.69 & 0.95 & $I \cdot 3 I$ & $1 \cdot 58$ & $I \cdot 73$ & I.89 \\
\hline 10 & 0.26 & 0.46 & 0.66 & 0.89 & $1 \cdot 28$ & $1 \cdot 55$ & $I \cdot 69$ & $1 \cdot 83$ \\
\hline 20 & 0.23 & 0.41 & 0.60 & 0.85 & $I \cdot 12$ & $1 \cdot 49$ & $x \cdot 67$ & $2 \cdot 12$ \\
\hline 30 & 0.20 & 0.35 & 0.54 & 0.77 & $1 \cdot 00$ & $1 \cdot 29$ & $I \cdot 46$ & $I \cdot 9 I$ \\
\hline 40 & 0.19 & 0.30 & 0.47 & 0.69 & 0.93 & $\mathbf{I} \cdot \mathbf{I} 2$ & $I \cdot 30$ & $\mathrm{I} \cdot 77$ \\
\hline 50 & 0.17 & 0.23 & 0.42 & 0.65 & 0.81 & I.04 & $I \cdot 28$ & $I \cdot 43$ \\
\hline 60 & 0.12 & 0.18 & 0.40 & 0.59 & 0.76 & 0.99 & $I \cdot I 9$ & $1 \cdot 62$ \\
\hline 70 & 0.01 & 0.16 & 0.34 & 0.52 & 0.71 & 0.95 & 1.06 & $I \cdot 66$ \\
\hline 80 & 0.01 & O.II & 0.29 & 0.46 & 0.62 & 0.81 & 0.94 & $I \cdot 08$ \\
\hline 90 & 0.01 & 0.01 & 0.24 & 0.41 & 0.57 & 0.70 & 0.99 & $I \cdot 09$ \\
\hline 100 & 0.00 & 0.01 & 0.18 & 0.32 & 0.49 & 0.78 & 0.85 & 1.02 \\
\hline I 10 & 0.00 & 0.01 & 0.03 & 0.24 & 0.42 & 0.70 & 0.88 & 0.93 \\
\hline 120 & 0.00 & 0.01 & 0.02 & 0.16 & 0.34 & 0.61 & 0.71 & 0.77 \\
\hline 130 & 0.00 & 0.01 & 0.01 & 0.04 & 0.23 & 0.41 & 0.52 & 0.55 \\
\hline 140 & 0.00 & 0.00 & 0.01 & 0.03 & $0.1 \mathrm{I}$ & 0.21 & 0.26 & 0.46 \\
\hline 150 & 0.00 & 0.00 & 0.01 & 0.02 & 0.04 & 0.11 & 0.15 & 0.31 \\
\hline 160 & 0.00 & 0.00 & 0.01 & 0.02 & 0.04 & $0 \cdot 10$ & 0.13 & 0.22 \\
\hline 170 & 0.00 & 0.00 & 0.01 & 0.02 & 0.04 & 0.10 & 0.13 & 0.22 \\
\hline 180 & 0.00 & 0.00 & 0.00 & 0.02 & 0.04 & 0.08 & 0.12 & 0.22 \\
\hline 190 & 0.00 & 0.00 & 0.01 & 0.02 & 0.04 & 0.08 & 0.12 & 0.22 \\
\hline 200 & 0.00 & 0.00 & 0.01 & 0.02 & 0.04 & 0.08 & 0.12 & 0.22 \\
\hline 210 & 0.00 & 0.00 & 0.01 & 0.02 & 0.04 & 0.08 & 0.12 & 0.22 \\
\hline 220 & 0.00 & 0.00 & 0.01 & 0.02 & 0.05 & 0.14 & 0.33 & 0.66 \\
\hline 230 & 0.00 & 0.00 & 0.01 & 0.02 & 0.06 & 0.28 & 0.62 & 0.97 \\
\hline 240 & 0.00 & 0.00 & 0.01 & 0.03 & 0.13 & 0.57 & 0.79 & I.04 \\
\hline 250 & 0.00 & 0.01 & 0.01 & 0.10 & 0.58 & 0.95 & $I \cdot 25$ & $\mathbf{I} \cdot 87$ \\
\hline 260 & 0.00 & 0.01 & 0.06 & 0.49 & 0.84 & $\mathbf{I} \cdot \mathbf{I} \mathbf{I}$ & $I \cdot 4 I$ & $1 \cdot 55$ \\
\hline 270 & 0.01 & 0.02 & 0.37 & 0.64 & 0.95 & $1 \cdot 39$ & I. 42 & $1 \cdot 64$ \\
\hline 280 & 0.01 & 0.29 & 0.44 & 0.71 & 0.98 & $1 \cdot 36$ & $I \cdot 44$ & $\mathrm{I} \cdot 64$ \\
\hline 290 & 0.01 & 0.29 & 0.45 & 0.72 & $1 \cdot 04$ & $1 \cdot 31$ & $I \cdot 5 I$ & $I \cdot 6 I$ \\
\hline 300 & 0.17 & 0.28 & 0.47 & 0.75 & $1 \cdot 08$ & $\mathbf{r} \cdot 33$ & $1 \cdot 59$ & 1.65 \\
\hline 310 & 0.24 & 0.32 & 0.50 & 0.79 & $I \cdot I 4$ & $\mathbf{I} \cdot \mathbf{3} \mathbf{I}$ & $I \cdot 68$ & $1 \cdot 79$ \\
\hline 320 & 0.25 & 0.33 & 0.56 & 0.82 & $\mathrm{I} \cdot 18$ & $1 \cdot 48$ & $\mathrm{I} \cdot 87$ & $1 \cdot 93$ \\
\hline 330 & 0.26 & 0.33 & 0.58 & 0.89 & $I \cdot 24$ & $1 \cdot 63$ & $2 \cdot 04$ & $2 \cdot 28$ \\
\hline 340 & 0.28 & $0.3^{8}$ & 0.67 & 0.94 & $1 \cdot 29$ & $\mathrm{I} \cdot 74$ & $I \cdot 93$ & $\mathrm{I} \cdot 98$ \\
\hline 350 & 0.33 & 0.41 & 0.62 & I.OI & $I \cdot 3 \mathbf{I}$ & $1 \cdot 63$ & $I \cdot 77$ & $\mathbf{I} \cdot 97$ \\
\hline
\end{tabular}

respectively. These data, together with analogous data for the loops connecting 97th and 99th percentiles, are presented in Table 4.

Since left ventricular hypertrophy tends to manifest itself in increased forces in the left posterior quadrant of the horizontal vector loop, this quadrant alone was used to analyse the loops for the patients with aortic stenosis. Table 4 shows that the use of this quadrant alone has an estimated specificity of 93 per cent with the loop connecting the 95th percentiles. Of the 20 patients with aortic stenosis, I7 showed a positive result with this procedure (Fig. 5), corresponding to a sensitivity of 85 per cent in this small group of patients studied. Two of the remaining 3 patients exceeded the 95th percentile limit in the right posterior quadrant.

To evaluate the ability to assess right ventricular hypertrophy, right posterior and right anterior quadrants were considered 




FIG. I The percentile chart for the horizontal plane of the Frank vector-

cardiogram of IOI normal children. See text for detailed description.

jointly. The combined specificity of these two quadrants for normal subjects is 89 per cent using the loop connecting the 95th percentiles (Table 4). Nineteen of the 20 patients with pulmonary stenosis showed a positive value in the right posterior quadrant, and the remaining patient was positive in the right anterior quadrant (Fig. 6). Thus, for these 20 patients with pulmonary stenosis, the $95^{\text {th }}$ percentile limit in the right anterior and right posterior quadrants gave a sensitivity of 100 per cent.

\section{Discussion}

Variations of the $Q R S$ voltages in the planar projections in normal children can be expressed as percentile values in various directions, and they can also be presented graphically as percentile-connecting loops. When such a loop is used as an appropriately calibrated transparency, a quick visual evaluation may be made by superimposition of the reference loop onto the vector loop to be analysed, scanning the loop for excessive voltages.

In an initial test, the ability of the system

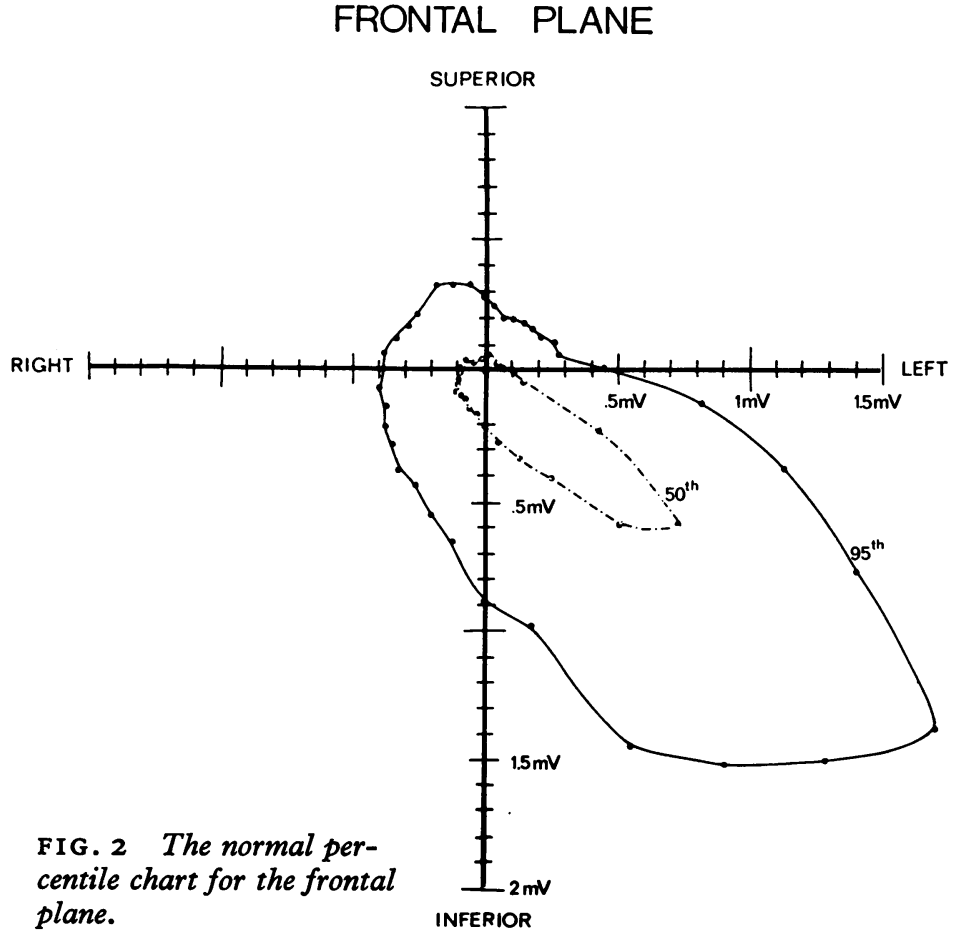




\section{LEFT SAGITTAL PLANE}

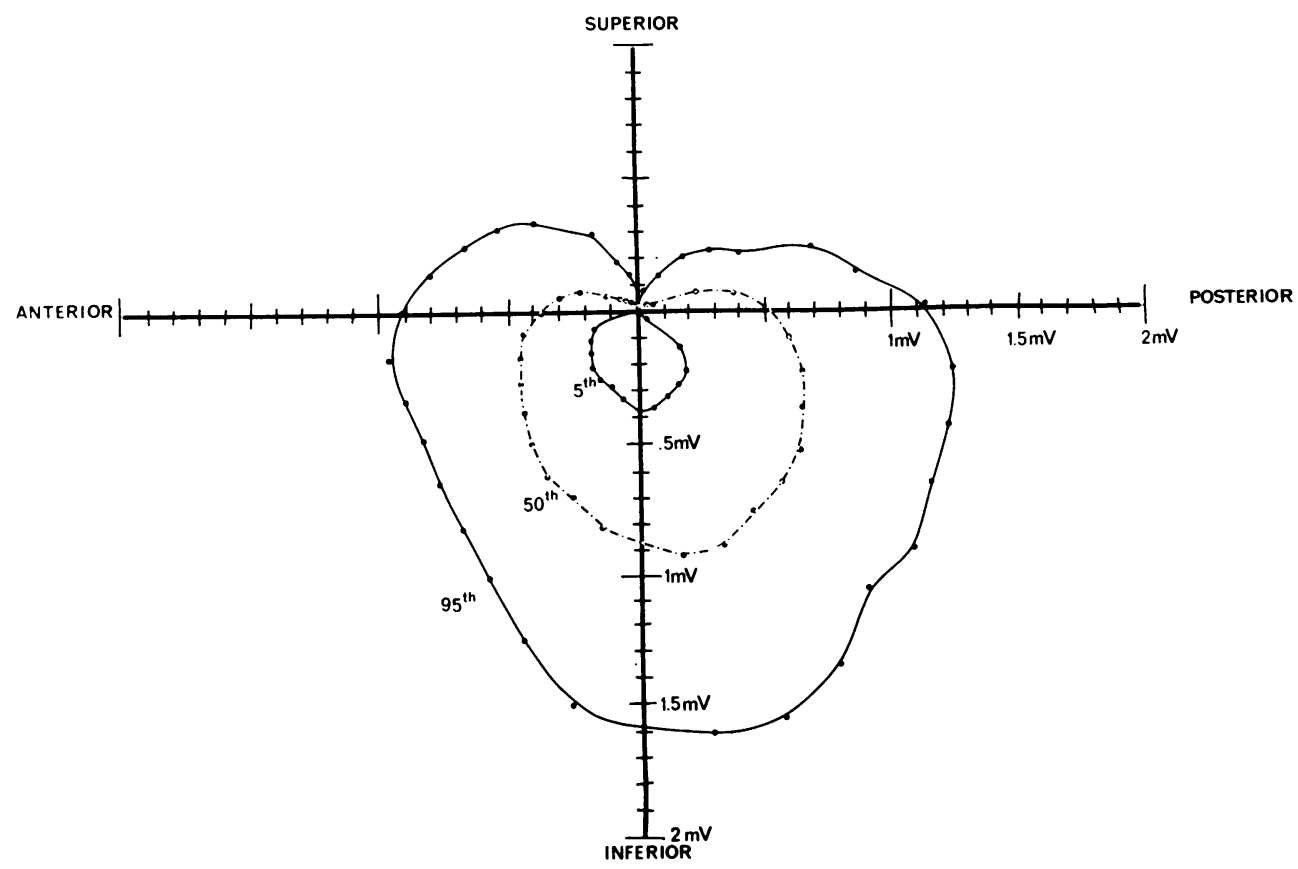

FIG. 3 The normal percentile chart for the left sagittal plane.


FIG. 4 The horizontal loop of a patient with valvar aortic stenosis shown on the left. On the right, an appropriately calibrated percentile chart for the horizontal plane is superimposed. It can be seen that the patient's vectorcardiogram greatly exceeds the 95th percentile limit in the left posterior quadrant. 
FIG. 5 The result of superimposition of the horizontal plane percentile chart on the loops of 20 patients with aortic stenosis is shown. The points inside the 95th percentile loop indicate maximum voltage of the patient's loop in that quadrant. The points outside the 95th percentile represent the voltage and direction where the voltage excess was maximum. It can be seen that the normal 95th percentile reference loop is exceeded in the left posterior quadrant by 17 of the 20 patients.

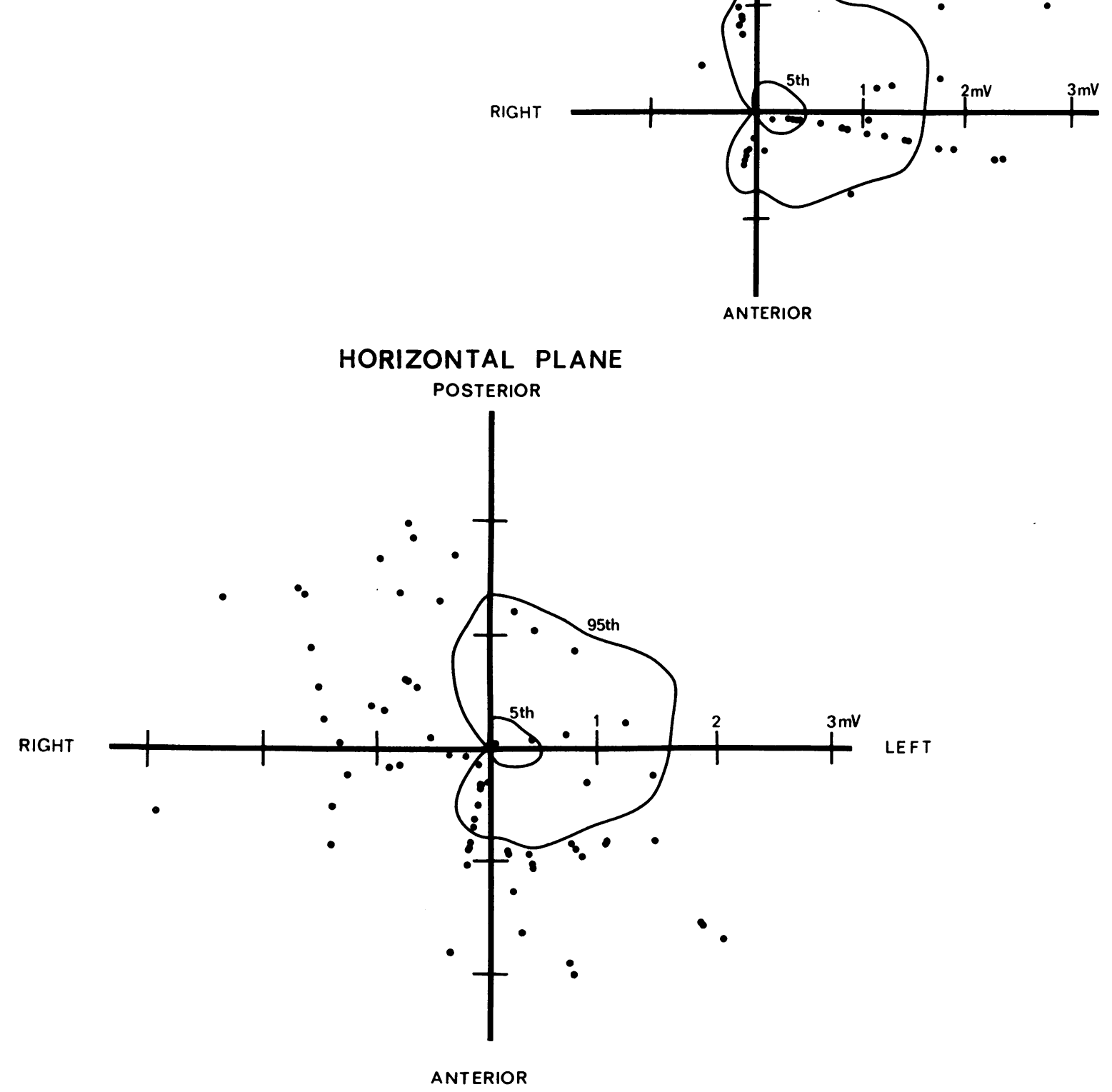

FIG. 6 The result of superimposition of the horizontal plane percentile charts on the loops of 20 patients with pulmonary stenosis is shown. It can be seen that the normal 95th percentile is exceeded in the right posterior quadrant by 19 of the 20 patients. 
developed to diagnose right and left ventricular hypertrophy has been shown to be satisfactory. For example, with reference in the horizontal plane, 17 of the 20 patients $(85 \%)$ with aortic stenosis showed excessive voltages in the left posterior quadrant, as opposed to only 7 per cent of the normal subjects. The patients with pulmonary stenosis showed excessive voltages in the right posterior quadrant ( 19 of the 20 patients) and right anterior quadrant (one remaining patient), while II per cent of the normal subjects showed such voltages. The patients in this study had lesions varying from mild to severe. The inclusion of greater numbers of patients with trivial disease would be expected to increase the false negative rate, thus decreasing the sensitivity of the system.

It is concluded that the graphic method described, using percentile vector charts, permits large numbers of vector loops to be analysed quickly. The method seems to be a reasonably sensitive one for detecting abnormality without having to do more complex and time-consuming measurements.

\section{References}

Frank E. (1956). An accurate, clinically practical system for spatial vectorcardiography. Circulation, 13, 737.

Gamboa, R., Hugenholtz, P. G., and Nadas, A. S. (1965). Comparison of electrocardiograms and vectorcardiograms in congenital aortic stenosis. British Heart fournal, 27, 344

Hellerstein, H. K., and Hamlin, R. (1960). QRS component of the spatial vectorcardiograms and of the spatial magnitude and velocity electrocardiograms of the normal dog. American fournal of Cardiology, 6, ro49.

Hugenholtz, P. G., and Liebman, J. (1962). The orthogonal vectorcardiogram in 100 normal children (Frank system). Circulation, 26, 891

Young, E., Liebman, J., and Nadas, A. S. (I960). The normal vectorcardiogram of children. American fournal of Cardiology, 5, 457.
TABLE 2 Frontal plane: vector values in millivolts

\begin{tabular}{|c|c|c|c|c|c|c|c|c|}
\hline \multirow{2}{*}{$\begin{array}{l}\text { Angle } \\
\text { in } \\
\text { degrees }\end{array}$} & \multicolumn{8}{|c|}{ Percentiles } \\
\hline & $\begin{array}{l}\text { Mini- } \\
\text { mum }\end{array}$ & 5 & 20 & 50 & 80 & 95 & 99 & $\begin{array}{l}\text { Maxi- } \\
\text { mum }\end{array}$ \\
\hline 0 & 0.00 & 0.00 & 0.00 & 0.06 & 0.18 & 0.45 & 0.54 & 0.87 \\
\hline 10 & 0.00 & 0.00 & 0.00 & O.I I & 0.33 & 0.83 & 0.98 & $\mathbf{I} \cdot \mathbf{I} \mathbf{I}$ \\
\hline 20 & 0.00 & 0.00 & 0.00 & 0.15 & 0.58 & $I \cdot I 9$ & $\mathrm{I} \cdot 78$ & $2 \cdot 00$ \\
\hline 30 & 0.00 & 0.00 & 0.01 & 0.48 & I.07 & $I \cdot 8 I$ & $2 \cdot 12$ & $2 \cdot 78$ \\
\hline 40 & 0.00 & 0.00 & 0.28 & 0.94 & $x \cdot 66$ & $2 \cdot 19$ & 2.57 & $3 \cdot 16$ \\
\hline 50 & 0.00 & 0.01 & 0.31 & 0.77 & $I \cdot 4 I$ & I.97 & $2 \cdot 27$ & $2 \cdot 36$ \\
\hline 60 & 0.00 & 0.01 & 0.20 & $0.4^{8}$ & $\mathbf{I} \cdot 07$ & $I \cdot 76$ & $2 \cdot 04$ & $2 \cdot 57$ \\
\hline 70 & 0.00 & 0.01 & 0.16 & 0.36 & 0.75 & $\mathrm{I} \cdot 55$ & I.75 & $x \cdot 82$ \\
\hline 80 & 0.00 & 0.01 & 0.11 & 0.29 & 0.53 & $I \cdot O I$ & $\mathbf{I} \cdot \mathbf{2 7}$ & $I \cdot 4 I$ \\
\hline 90 & 0.00 & 0.01 & 0.04 & 0.21 & 0.42 & 0.89 & 0.98 & I. 44 \\
\hline 100 & 0.00 & 0.01 & 0.02 & 0.18 & 0.34 & 0.68 & 0.90 & $I \cdot 33$ \\
\hline IIO & 0.00 & 0.01 & 0.02 & 0.16 & 0.29 & 0.60 & 0.76 & 1.03 \\
\hline 120 & 0.00 & 0.01 & 0.01 & 0.14 & 0.26 & 0.52 & 0.69 & 0.82 \\
\hline 130 & 0.00 & 0.01 & 0.01 & 0.14 & 0.24 & 0.47 & 0.63 & 0.77 \\
\hline 140 & 0.00 & 0.01 & 0.12 & 0.12 & 0.22 & 0.43 & 0.59 & 0.77 \\
\hline 150 & 0.00 & 0.01 & 0.01 & O.I I & 0.22 & 0.40 & 0.56 & 0.76 \\
\hline 160 & 0.00 & 0.00 & 0.01 & O. I I & 0.23 & 0.40 & 0.52 & 0.73 \\
\hline 170 & 0.00 & 0.00 & 0.01 & 0.09 & 0.23 & 0.40 & 0.51 & 0.70 \\
\hline 180 & 0.00 & 0.00 & 0.01 & 0.09 & 0.23 & 0.39 & 0.54 & 0.68 \\
\hline 190 & 0.00 & 0.00 & 0.01 & 0.09 & 0.22 & 0.35 & 0.50 & 0.52 \\
\hline 200 & 0.00 & 0.00 & 0.01 & 0.06 & 0.23 & 0.33 & $0.4 \mathrm{I}$ & 0.48 \\
\hline 210 & 0.00 & 0.00 & 0.01 & 0.03 & 0.23 & 0.32 & 0.38 & 0.44 \\
\hline 220 & 0.00 & 0.00 & 0.01 & 0.04 & 0.23 & $0.4 \mathrm{I}$ & 0.47 & 0.67 \\
\hline 230 & 0.00 & 0.00 & 0.01 & 0.04 & 0.23 & 0.38 & 0.46 & 0.52 \\
\hline 240 & 0.00 & 0.00 & 0.01 & 0.03 & 0.23 & 0.35 & 0.41 & 0.55 \\
\hline 250 & $0 . \infty 0$ & 0.00 & 0.01 & 0.03 & 0.21 & 0.33 & 0.37 & 0.54 \\
\hline 260 & 0.00 & 0.00 & 0.01 & 0.04 & 0.18 & 0.33 & 0.36 & 0.40 \\
\hline 270 & 0.00 & 0.00 & 0.01 & 0.04 & 0.14 & 0.28 & 0.31 & 0.40 \\
\hline 280 & 0.00 & 0.00 & 0.01 & 0.04 & 0.14 & 0.24 & 0.28 & 0.33 \\
\hline 290 & 0.00 & 0.00 & 0.01 & 0.05 & 0.12 & 0.20 & 0.25 & 0.33 \\
\hline 300 & 0.00 & 0.00 & 0.01 & 0.06 & 0.12 & 0.23 & 0.24 & 0.33 \\
\hline 310 & 0.00 & 0.00 & 0.01 & 0.05 & 0.12 & 0.23 & 0.24 & 0.35 \\
\hline 320 & 0.00 & 0.00 & 0.01 & 0.05 & 0.12 & 0.23 & 0.30 & 0.35 \\
\hline 330 & 0.00 & 0.00 & 0.01 & 0.04 & 0.12 & 0.24 & 0.30 & 0.40 \\
\hline 340 & 0.00 & 0.00 & 0.01 & 0.05 & 0.12 & 0.29 & 0.40 & 0.56 \\
\hline 350 & 0.00 & 0.00 & 0.01 & 0.04 & 0.14 & 0.31 & 0.44 & 0.66 \\
\hline
\end{tabular}

Requests for reprints to Dr. R. S. Jones, Alder Hey Children's Hospital, Eaton Road, Liverpool, LI2 2 AP.

Note: Tables 3 and 4 are overleaf. 
TABLE 3 Left sagittal plane: vector values in millivolts

\begin{tabular}{|c|c|c|c|c|c|c|c|c|}
\hline \multirow{2}{*}{$\begin{array}{l}\text { Angle } \\
\text { in } \\
\text { degrees }\end{array}$} & \multicolumn{8}{|c|}{ Percentiles } \\
\hline & $\begin{array}{l}\text { Mini- } \\
\text { mum }\end{array}$ & 5 & 20 & 50 & 80 & 95 & 99 & $\begin{array}{l}\text { Maxi- } \\
\text { mum }\end{array}$ \\
\hline 0 & 0.00 & 0.00 & 0.02 & 0.50 & 0.85 & $I \cdot 12$ & $I \cdot 26$ & $I \cdot 68$ \\
\hline IO & 0.00 & 0.00 & 0.23 & 0.60 & 0.98 & $I \cdot 26$ & $I \cdot 42$ & $I \cdot 63$ \\
\hline 20 & 0.00 & 0.00 & 0.34 & 0.68 & 0.99 & $I \cdot 29$ & $1 \cdot 38$ & $I \cdot 63$ \\
\hline 30 & 0.00 & 0.00 & 0.39 & 0.74 & $1 \cdot 08$ & $I \cdot 32$ & $I \cdot 40$ & $1 \cdot 46$ \\
\hline 40 & 0.00 & 0.21 & 0.48 & 0.82 & $\mathbf{I} \cdot \mathbf{I} 3$ & $I \cdot 4 I$ & $1 \cdot 48$ & $I \cdot 80$ \\
\hline 50 & 0.21 & 0.30 & 0.55 & 0.86 & $1 \cdot 24$ & $I \cdot 48$ & I.79 & 2.05 \\
\hline 60 & 0.22 & 0.32 & 0.60 & 0.88 & $\mathbf{I} \cdot 30$ & $I \cdot 56$ & $I \cdot 73$ & $2 \cdot I I$ \\
\hline 70 & 0.24 & 0.34 & 0.62 & 0.95 & $I \cdot 36$ & $I \cdot 65$ & $I \cdot 80$ & $2 \cdot 12$ \\
\hline 80 & 0.32 & 0.37 & 0.61 & 0.94 & $I \cdot 34$ & $1 \cdot 63$ & $\mathrm{I} \cdot 75$ & 2.02 \\
\hline 90 & 0.30 & 0.38 & 0.58 & 0.88 & $1 \cdot 28$ & $1 \cdot 58$ & $I \cdot 80$ & $2 \cdot 17$ \\
\hline 100 & 0.28 & 0.34 & 0.58 & 0.84 & $I \cdot I 4$ & $\mathrm{I} \cdot 53$ & $2 \cdot 07$ & $2 \cdot 31$ \\
\hline IIO & 0.27 & 0.30 & 0.48 & 0.75 & $1 \cdot 03$ & $I \cdot 30$ & $I \cdot 64$ & I.89 \\
\hline 120 & 0.24 & 0.29 & 0.44 & 0.72 & 0.94 & $I \cdot I 7$ & $I \cdot 36$ & $I \cdot 54$ \\
\hline 130 & 0.21 & 0.27 & 0.42 & 0.65 & 0.86 & I.07 & $I \cdot 26$ & $I \cdot 49$ \\
\hline 140 & 0.22 & 0.24 & 0.40 & 0.59 & 0.85 & $\mathrm{I} \cdot 02$ & $I \cdot 13$ & $I \cdot 45$ \\
\hline I50 & 0.09 & 0.21 & 0.36 & 0.53 & 0.78 & 0.97 & $\mathbf{I} \cdot \mathbf{I O}$ & $1 \cdot 35$ \\
\hline 160 & 0.01 & 0.18 & 0.32 & 0.49 & 0.77 & 0.97 & I.06 & $I \cdot 38$ \\
\hline 170 & 0.01 & 0.03 & 0.23 & 0.45 & 0.75 & 0.99 & I.06 & $I \cdot 44$ \\
\hline 180 & 0.01 & 0.01 & 0.15 & 0.37 & 0.67 & 0.92 & $\mathbf{I} \cdot \mathbf{I O}$ & $I \cdot I 4$ \\
\hline 190 & 0.01 & 0.01 & 0.03 & 0.31 & 0.55 & 0.83 & $1 \cdot 02$ & I. I3 \\
\hline 200 & 0.01 & 0.01 & 0.03 & 0.24 & 0.43 & 0.72 & 0.93 & $1 \cdot 08$ \\
\hline 210 & 0.01 & 0.01 & 0.03 & 0.14 & 0.36 & 0.63 & 0.69 & 0.80 \\
\hline 220 & 0.01 & 0.01 & 0.03 & 0.08 & 0.27 & 0.52 & 0.59 & 0.63 \\
\hline 230 & 0.01 & 0.01 & 0.03 & 0.05 & 0.20 & 0.40 & 0.50 & $0.5 \mathrm{I}$ \\
\hline 240 & 0.01 & 0.01 & 0.03 & 0.04 & 0.12 & 0.34 & 0.41 & 0.46 \\
\hline 250 & 0.01 & 0.01 & 0.03 & 0.04 & 0.09 & 0.19 & 0.34 & 0.37 \\
\hline 260 & 0.01 & 0.01 & 0.02 & 0.03 & 0.06 & 0.14 & 0.23 & 0.34 \\
\hline 270 & 0.01 & 0.01 & 0.02 & 0.03 & 0.05 & 0.09 & 0.16 & 0.34 \\
\hline 280 & 0.01 & 0.01 & 0.02 & 0.03 & 0.05 & 0.09 & 0.12 & 0.34 \\
\hline 290 & 0.00 & 0.01 & 0.02 & 0.03 & 0.05 & 0.09 & 0.12 & 0.34 \\
\hline 300 & 0.00 & 0.01 & 0.02 & 0.03 & 0.05 & 0.16 & 0.34 & 0.49 \\
\hline 310 & 0.00 & 0.01 & 0.02 & 0.03 & 0.08 & 0.27 & 0.38 & 0.74 \\
\hline 320 & 0.00 & 0.01 & 0.02 & 0.04 & 0.18 & 0.36 & 0.40 & 0.97 \\
\hline 330 & 0.00 & 0.01 & 0.02 & 0.05 & 0.30 & 0.45 & 0.57 & $I \cdot 04$ \\
\hline 340 & 0.01 & 0.02 & 0.03 & 0.24 & 0.50 & 0.72 & I.08 & $I \cdot I 8$ \\
\hline 350 & 0.01 & 0.02 & 0.04 & 0.38 & 0.68 & 0.79 & 0.87 & $I \cdot 6 I$ \\
\hline
\end{tabular}

TABLE 4 False positive rate in horizontal plane (normal subjects)

\begin{tabular}{|c|c|c|c|c|c|c|c|c|c|c|}
\hline $\begin{array}{l}\text { 95th } \\
\text { 97th } \\
\text { 99th }\end{array}$ & $\begin{array}{l}22 \\
16 \\
13\end{array}$ & $\begin{array}{l}78 \\
84 \\
87\end{array}$ & $\begin{array}{l}7 \\
5 \\
3\end{array}$ & $\begin{array}{l}93 \\
95 \\
97\end{array}$ & $\begin{array}{l}3 \\
2 \\
2\end{array}$ & $\begin{array}{l}97 \\
98 \\
98\end{array}$ & $\begin{array}{l}8 \\
7 \\
6\end{array}$ & $\begin{array}{l}92 \\
93 \\
94\end{array}$ & $\begin{array}{l}7 \\
6 \\
4\end{array}$ & $\begin{array}{l}93 \\
94 \\
96\end{array}$ \\
\hline
\end{tabular}

